\title{
Influence of selected ITS services on the driver's behaviour - results of simulation test carried out on top-of-the-range driving simulators
}

\author{
Tomasz Kamiński ${ }^{* 1}$, Małgorzata Pędzierska ${ }^{1}$, Przemysław Filipek ${ }^{2}$ \\ ${ }^{1}$ Motor Transport Institute, 80 Jagiellonska Str., 03-301 Warsaw, Poland \\ ${ }^{2}$ Lublin University of Technology, 38D Nadbystrzycka Str., 20 - 618 Lublin, Poland
}

\begin{abstract}
The publication is a summary of the test results, using top-ofthe-range driving simulators in RID 4D project. Experiment methodology and example of research results were presented in the article entitled: "The use of simulator studies to assess the impact of ITS services on the behaviour of the road users". The project was implemented as part of the Road Innovation Development (RID) program organized and financed by the National Centre for Research and Development and General Directorate of National Roads and Motorways (contract No. DZP/RID-I$41 / 7 / \mathrm{NCBR} / 2016$ ). The results of the research were used to assess the impact of ITS services on the driver's behaviour and to calibrate the simulation software Visum/Saturn/Vissim. The result of a series of experiments is a set of data including speed, speed changes, the length of the road section on which the driver maintained constant speed and additional information on the driver's behaviour. Information for the drivers was presented on boards and signs of variable content. The vehicle speed was analyzed along a distance of $200 \mathrm{~m}, 30 \mathrm{~m}$, and then at the location spot of the variable content sign/board and $200 \mathrm{~m}$ after the sign. The data was also recorded in the case of the traditional speed-limiting sign.
\end{abstract}

\section{Introduction}

The article presents selected results of the research carried out as part of the RID 4D project (contract number DZP/RID-I-41/7/NCBR/2016), implemented as part of the Road Innovation Development Program, financed jointly by the National Centre for Research and Development and the General Directorate of National Roads and Highways. One of the elements of the project was to determine the impact of information provided via road signs to the drivers, on the road safety, in particular on the behavior of drivers.

For this purpose, the research has been carried out using high-end driving simulators that Motor Transport Institute has at its disposal. The results of the measurements made it possible to determine the impact of information and commands transmitted via traffic signs on the behavior of the drivers. The results of these measurements were then used to calibrate the micro, meso- and macrosymulation software for the road traffic, covering single

* Corresponding author: tomasz.kaminski@its.waw.pl 
intersections, road sections and areas. Simulation tests were carried out by the Gdańsk University of Technology which is one of the members of the consortium implementing the project.

\section{Research using a high-end driving simulator}

The AS 1200-6 simulator of the passenger car was used to conduct the research on the point influence of the sign posting on the behavior of the drivers (Figure 1).

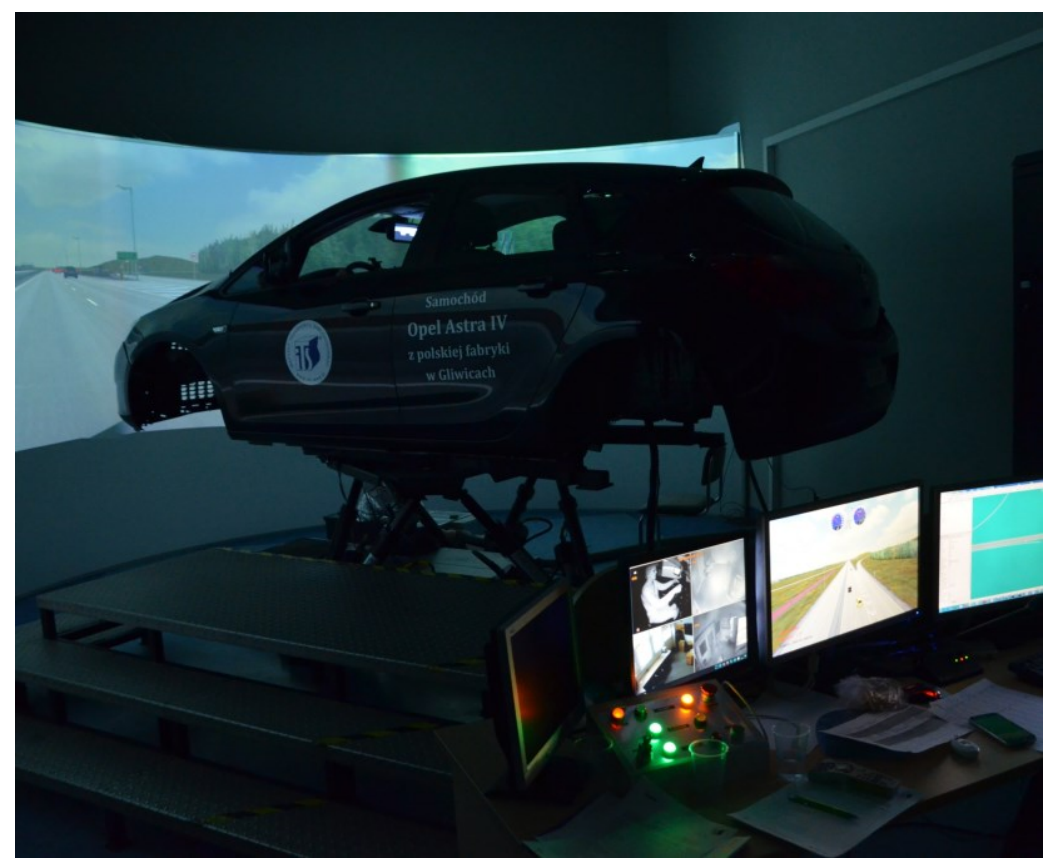

Fig. 1. Top-of-the-range AS 1200-6 driving simulator.

The simulator was built based on the Opel Astra passenger car body installed on a platform with six degrees of freedom. It enables realistic simulation of car driving. Thanks to the software modifications made by the Motor Transport Institute, it is possible to reproduce road infrastructure in the simulator complying with the Polish legal conditions and traffic realities.

In the case of Intelligent Transport Systems, information and commands are passed on to the drivers using boards and variable message signs. In order to determine the impact of this type of devices on the behavior of drivers, in the simulation environment four research scenarios were developed, within which three to six boards or variable message signs were included. In one case, traditional static signs with speed limit were used. The boards presented information for the drivers about the current traffic situation, speed limits and manoeuvre commands. A detailed description of the presented contents is presented in Table 1.

Table 1. Simulation scenarios with information and commands for drivers. 


\begin{tabular}{|c|c|c|c|c|c|c|}
\hline $\begin{array}{l}\text { SCE- } \\
\text { NA- } \\
\text { RIO }\end{array}$ & $\begin{array}{c}\text { GANTRY } \\
1\end{array}$ & $\begin{array}{c}\text { GANTRY } \\
2\end{array}$ & $\begin{array}{c}\text { GANTRY } \\
\mathbf{3}\end{array}$ & $\begin{array}{c}\text { GANTRY } \\
4\end{array}$ & $\begin{array}{c}\text { GANTRY } \\
5\end{array}$ & $\begin{array}{c}\text { GANTRY } \\
6\end{array}$ \\
\hline 1 & $\begin{array}{l}\text { Alternative } \\
\text { route and } \\
\text { times } \\
\text { information, } \\
\text { sometimes a } \\
\text { few percent } \\
\text { difference }\end{array}$ & $\begin{array}{l}\text { Speed limit } \\
\text { on the board }\end{array}$ & $\begin{array}{c}\text { Slippery } \\
\text { - inscription } \\
\text { and } \\
\text { pictogram }\end{array}$ & - & - & - \\
\hline 2 & $\begin{array}{l}\text { Alternative } \\
\text { route, } \\
\text { recommende } \\
\text { d detour }\end{array}$ & Blocked lane & Strong wind & $\begin{array}{l}\text { Accident, } \\
\text { change the } \\
\text { lane }\end{array}$ & $\begin{array}{l}\text { Speed limit } \\
\text { with the } \\
\text { reason for } \\
\text { the } \\
\text { restriction }\end{array}$ & - \\
\hline 3 & - & $\begin{array}{l}\text { Fog, slow } \\
\text { down }\end{array}$ & $\begin{array}{l}\text { Accident, } \\
\text { change lane } \\
\text { and speed } \\
\text { limit }\end{array}$ & $\begin{array}{l}\text { Restriction } \\
\text { on the board } \\
\text { and on the } \\
\text { sign (sign at } \\
\text { the next } \\
\text { gantry) }\end{array}$ & $\begin{array}{l}\text { Dynamic } \\
\text { sign }\end{array}$ & $\begin{array}{l}\text { Alternative } \\
\text { route, } 2 \text {-fold } \\
\text { time } \\
\text { difference }\end{array}$ \\
\hline 0 & $\begin{array}{l}\text { Strong wind, } \\
\text { no } \\
\text { information }\end{array}$ & $\begin{array}{l}\text { Fog, without } \\
\text { information }\end{array}$ & $\begin{array}{c}\text { Accident } \\
\text { without } \\
\text { information }\end{array}$ & $\begin{array}{c}\text { Slippery } \\
\text { without } \\
\text { information }\end{array}$ & $\begin{array}{c}\text { Static } \\
\text { restriction }\end{array}$ & $\begin{array}{l}\text { Alternative } \\
\text { route without } \\
\text { dynamic } \\
\text { information }\end{array}$ \\
\hline
\end{tabular}

Patterns of boards and signs with variable message were designed in accordance with the document prepared by the General Directorate for National Roads and Motorways entitled "Model messages for variable message signs under module 3.2.1.14.4: Providing information and instructions for the drivers with requirements for gantry support structures", published on March 27, 2017 (version 2). Table 2 contains a list of boards and signs analyzed in the first place.

Table 2. Signs in scenarios analysed in first investigation.

\begin{tabular}{|c|c|}
\hline Type of sign & Graphic content \\
\hline Speed limit on the board & \\
$\begin{array}{c}\text { Speed limit with the reason for the } \\
\text { restriction }\end{array}$ & \\
\hline
\end{tabular}




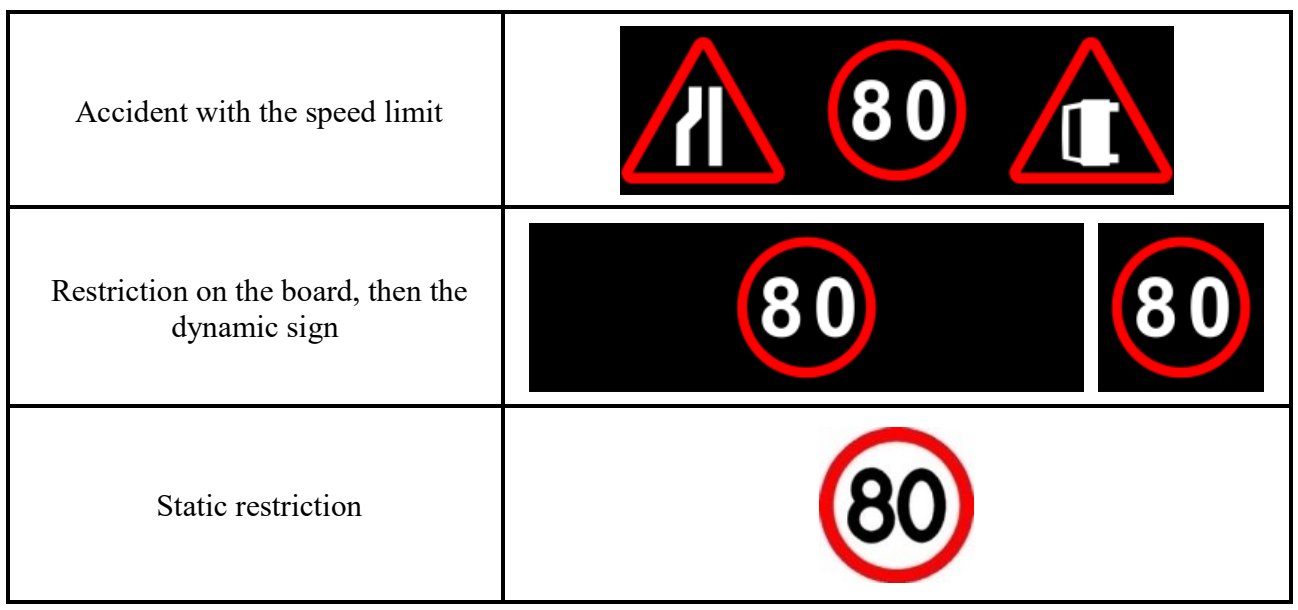

The group of persons examined included a total of 60 people. Three age ranges were used - 18-25, 26-49 and 50+, containing the same number of people. Out of the people surveyed, 30 of them drove in good weather conditions, while another 30 in bad conditions during rainfall. The aim of such a division was to determine the impact of weather conditions on the reactions of the drivers.

The simulator allows to register a number of parameters related to driving, such as vehicle speed, acceleration and braking intensity, staying in the lane (distance of the longitudinal axis of the car from the lane axis), time to the collision with other vehicles and road infrastructure objects, lane change, switching turn indicators on or off, the degree of pressing the acceleration, brake or clutch pedal. On the other hand, the most interesting value from the point of view of the impact on the road safety was the speed of the vehicle in the area of impact of the board or sign limiting the speed placed on the variable message board, on the sign with variable message or on the static sign with the speed limit. Vehicle speed is one of the most important factors affecting road safety. The greater the difference in speed between vehicles or between vehicle and road infrastructure during a collision, the more serious the consequences of a potential collision.

\section{Results of the experiment}

In order to determine the way the boards and signs with variable message influence the drivers' behaviour, the speed of the vehicle was recorded. Based on the data recorded, the speed $V_{1}$ was determined at a distance of $200 \mathrm{~m}$ before the board or sign, speed $V_{2}$ at a distance of $30 \mathrm{~m}$ before the board or sign, speed $\mathrm{V}_{3}$ at the spot of the board or sign and speed $\mathrm{V}_{4}$ at a distance of $200 \mathrm{~m}$ behind the board or sign. From the point of view of the road safety, important is the driver's behaviour within the area of the board/road sign interaction. Therefore, based on the measurement data, $\Delta \mathrm{V}_{3}$ and $\Delta \mathrm{V}_{4}$ were calculated as the velocity difference in the place of the board/sign location and $200 \mathrm{~m}$ behind it, assuming as a reference the vehicle speed value $200 \mathrm{~m}$ in front of the board/sign (at that distance the driver did not yet see the speed limit and transmitted messages). Figure 2 shows a diagram showing the value of velocity and selected velocity decreases recorded. 


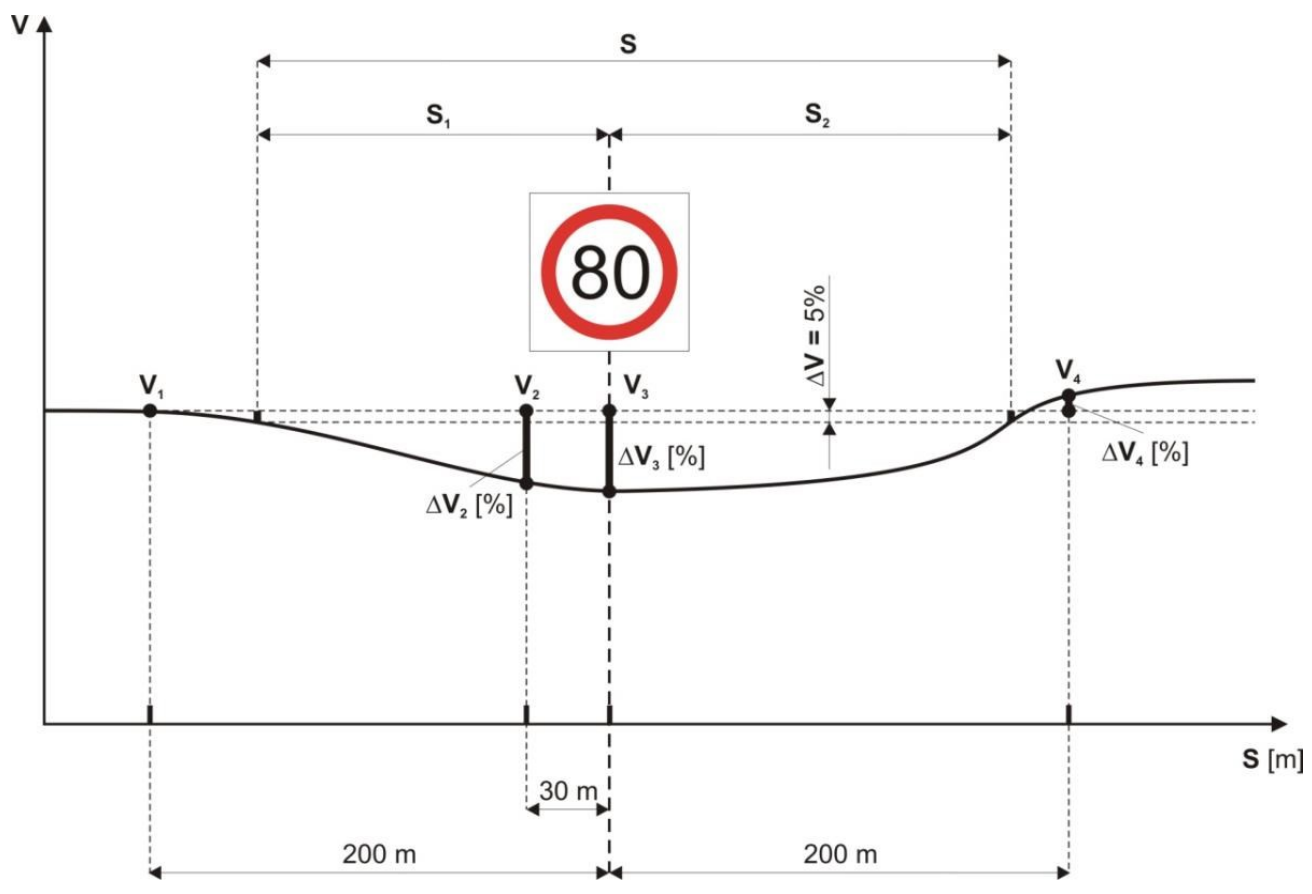

Fig. 2. Diagram of selected values of speeds and speed changes.

Statistical analysis of the research results is currently under way. Examples of cases that were analyzed include the marking described in Table 2 . The results of analyzes are presented in Table 3 and Figure 3.

Table 3. Result of the data analyzes.

\begin{tabular}{|l|r|r|r|}
\hline \multicolumn{1}{|c|}{ Type of signs } & $\square \mathbf{V}_{\mathbf{1}}$ & $\square \mathbf{V}_{\mathbf{2}}$ & $\square \mathbf{V}_{\mathbf{3}}$ \\
\hline Speed limit on the board & 2,06 & 3,69 & 13,57 \\
\hline Speed limit with a slippery roadway sign & 4,96 & 6,60 & 16,19 \\
\hline Speed limit with a road accident sign & 3,52 & 4,74 & 14,65 \\
\hline Restriction on the board, then VMS - speed limit & 3,48 & 3,62 & 5,19 \\
\hline Static restriction & 6,59 & 8,60 & 14,38 \\
\hline
\end{tabular}

As shown in Figure 3, already in the area preceding the board/sign and in the place of the board/sign location, the vehicles' speed reduction by several percent was obtained. However, for the speed measured $200 \mathrm{~m}$ behind the board/sign, there was a decrease of a dozen or so percent (about 14-16\%). In absolute terms, this translates into a vehicle speed reduction of approximately $10-12 \mathrm{~km} / \mathrm{h}$.

An exception is the case in which the variable message board was used followed by the variable message sign with the speed limit. The value of $\Delta \mathrm{V}_{4}$ was given for the variable message sign, which was placed approximately $1.5 \mathrm{~km}$ from the board. For this pair of ITS devices, an effect on drivers was obtained at the level of approx. 5\% (for the speed measurement made $200 \mathrm{~m}$ behind the sign). In this case, the drivers' reaction was definitely weaker than in the case of variable message boards/signs. 


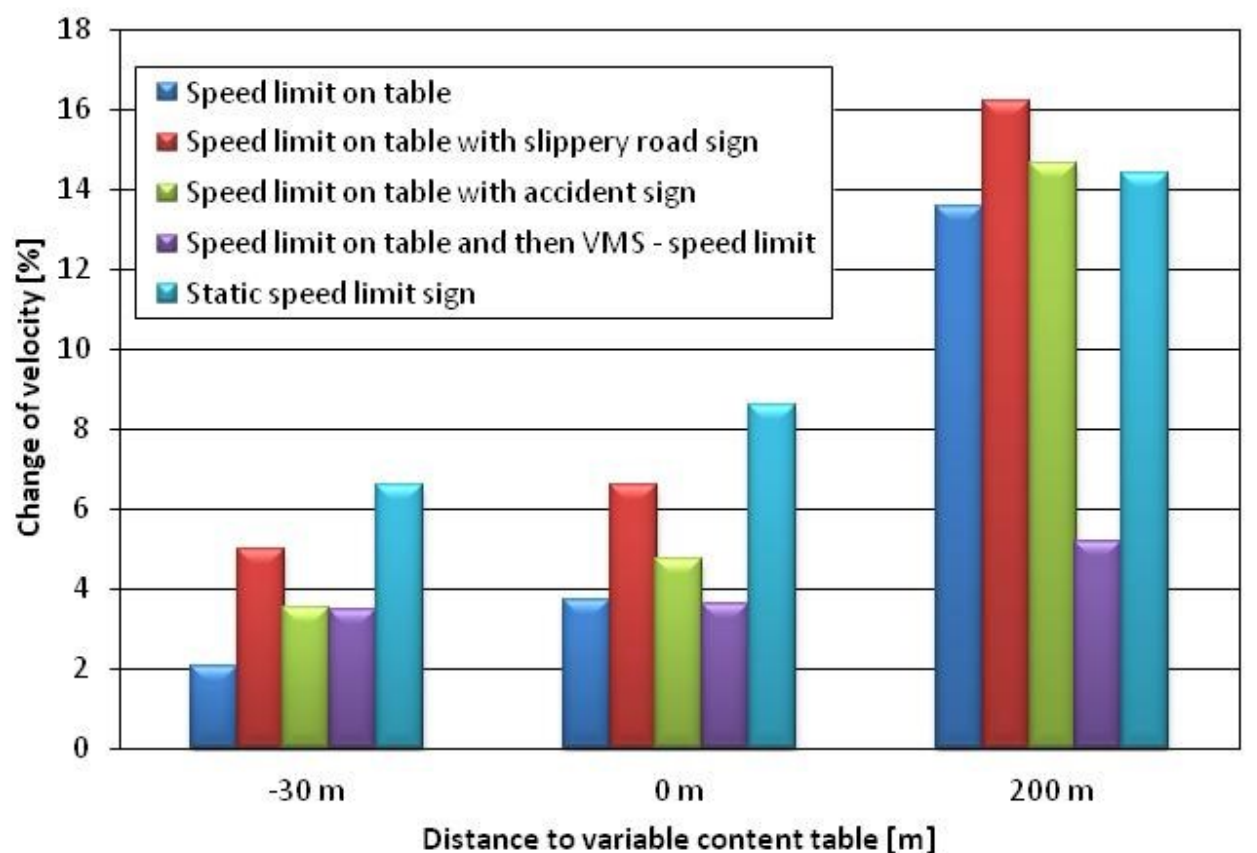

Fig. 3. Results of the analyses.

The highest impact was noted for the board showing the speed limit along with the reason for such a restriction - information about the slippery surface. It should also be noted that for the numerical data related to speed reduction, a high standard deviation value was noted. This proves a great diversity of drivers' behavior, who reacted more or less decisively to the speed limit sign. It also happened that they even accelerated when they saw the speed limit sign. However, these extreme behaviors were not considered as representative for the group of drivers examined.

Noteworthy is also the fact that the speed reduction obtained due to the use of a variable message board with the speed limit and the reduction obtained in the case of a static sign has a similar value. This means that wherever we do not care about the possibility of changing the displayed message of the road markings, static sign may be used with a similar effect.

Figure 4 shows an example comparison of the percentage speed reduction $\Delta \mathrm{V}_{4}$ for the board with speed limit displayed - for good and bad weather (rainfall). According to the data analysis, a higher level of reduction was obtained for good weather conditions. A similar situation was noted in the case of other boards and variable message signs analyzed. However, it should be noted that while the percentage reduction in speed in bad weather conditions is lower than in good weather conditions, the absolute speed values are similar. This is due to the fact that in the case of good weather conditions, the speeds obtained by vehicles are higher than in bad weather conditions. 


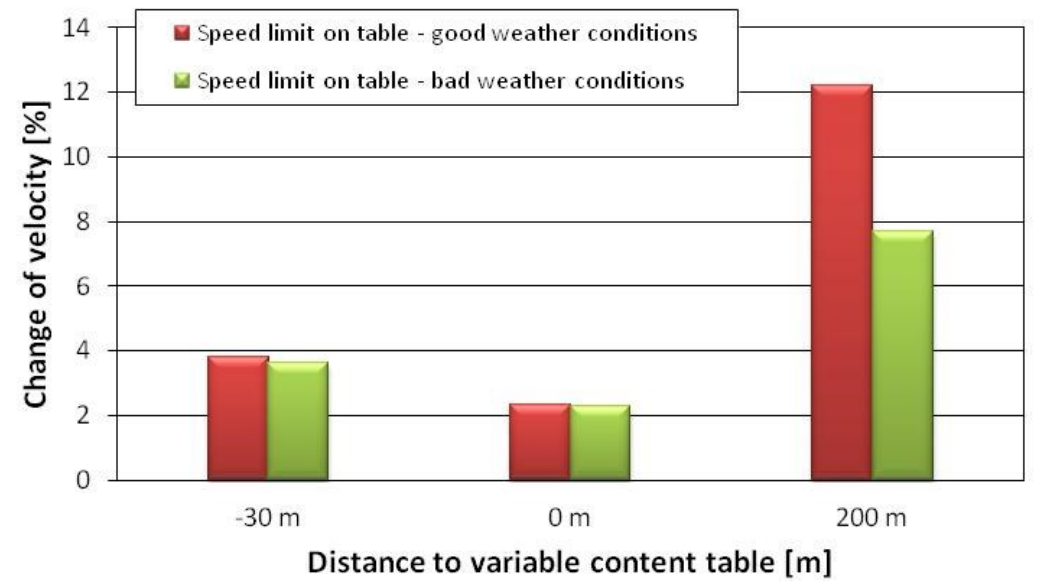

Fig. 4. Comparison of percentage change of car velocity during good and bad weather condition.

\section{Summary}

Thanks to the research carried out as part of the project, it was possible to determine the impact of boards and signs with variable message on the speed of vehicles. One of the conclusions resulting from the tests is a better impact of the speed-limiting sign, in the case when the drivers are also provided with information about the reason for the restriction. Drivers knowing that the restriction is justified better react to them.

On the other hand, the large standard deviation of the speed reduction percentage is significant. It seems that in justified cases, where it is particularly important to limit speed to protect the health and lives of road users, it may be necessary to use radar equipment to enforce the speed limit existing.

Obtained results of the measurements will be used to calibrate traffic simulation software. As a result of these simulations, it will be possible to determine the impact of ITS devices on the road traffic efficiency.

\section{References}

1. M. Kruszewski, P. Razin, M. Niezgoda, E. Smoczyńska, T. Kamiński, Simulator Sickness Occurrence and Effects Analysis During Drivers Research (in Polish), Syst. Logistyczne Wojsk. 44 pp. 188-201 (2016)

2. S. Mitkow, J. Sieczka, T.R. Waśniewski, T. Kamiński, Analysis of Road Incidents Involving Drivers Without Driver's License on the Background of the Road Safety (in Polish), Gospod. Mater. i Logistyka. pp. 452-468 (2016)

3. T. Kamiński, M. Siergiejczyk, J. Oskarbski, P. Filipek, Impact of ITS services on the safety and efficiency of road traffic, MATEC Web Conf. 122 pp. 03004 (2017). doi:10.1051/matecconf/201712203004

4. M. Pędzierska, T. Kamiński, K. Gąsiorek, E. Szmidt, P. Razin, The conception of evaluation of the impact of intelligent transport systems on road traffic safety and traffic efficiency with the use of a high class of driving simulators (in Polish), Autobusy. 6 pp. 1253-1257 (2017)

5. T. Kamiński, J. Oskarbski, Implementing ITS systems using the example of the city of Łódź and Bydgoszcz (in Polish), Transp. Samoch. 1 pp. 23-33 (2017) 